\title{
Effect of Antimicrobial Triclosan on Reproductive System of Male Rat
}

Fahar Ibtisham, Aamir Nawab, Yi Zhao, Guanghui Li, Mei Xiao and Lilong An*

Agricultural Collage, Guangdong Ocean University, Zhanjiang, Guangdong, China

*Corresponding author; Lilong An, Agricultural Collage, Guangdong Ocean University, Haida Road, Mazhang District, Zhanjiang 524088, Guangdong, China, Tel: +86-759-2383247; E-mail: anlilong@126.com

Received date: October 31, 2016; Accepted date: November 26, 2016; Published date: November 28, 2016

Copyright: (C) 2016 Ibtisham F, et al. This is an open-access article distributed under the terms of the Creative Commons Attribution License, which permits unrestricted use, distribution, and reproduction in any medium, provided the original author and source are credited.

\begin{abstract}
Triclosan (5-chloro-2-(2,4-dichlorophenoxy)phenol: TCS) is a synthetic, broad-spectrum antibacterial agent used in broad range of household and personal care products including hand soap, toothpaste, and deodorants. Recently, concerns have been raised over TCS's potential for endocrine and reproductive disruption. This review contains the information about deleterious toxic effects of TCS on reproductive system of male rat and the possible mechanism. The literature findings showed that TCS deadly affects the reproductive profile of male rats. According to literature TCS depress the testicular function of male rat including spermatogenesis and steroidogenesis by decreasing the

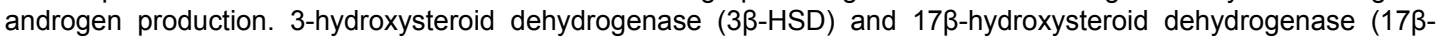
HSD) are two critical enzymes in the steroidogenesis pathway, while according to findings TCS treated rats had lowered concentration of androgen. TCS treated rats also showed significant lowered testicular weight, number of germ cells, Sertoli cells, Leydig Cells, primary spermatogonia, secondary spermatogonia, and spermatocytes. These observations suggest that TCS have degenerative and retrogressive effects on rat testes. Overall the literature findings showed that TCS decrease the production of androgen like testosterone, Luteinizing Hormone (LH) and FSH resulting decreased sperm production and histopathological changes.
\end{abstract}

Keywords: Triclosan; Toxicity; Spermatogenesis; Steroidogenesis; Male Rat

\section{Introduction}

Triclosan (5-chloro-2-(2,4-dichlorophenoxy)phenol: TCS) is an effective antifungal and antibacterial agent that is frequently used throughout the world in pharmaceuticals, personal care products, plastics, and fabrics [1]. TCS have effective response against many types of bacteria and fungi, it permeates the bacterial cell wall and targets multiple cytoplasmic and membrane sites, including RNA synthesis and the production of macromolecules, and it also blocks the synthesis of fatty acids [2]. TCS may be characterized as a halogenated aromatic hydrocarbon, containing phenol, diphenyl ether and polychlorinated biphenyl substructure [3]. The chemical structure of TCS is halogenated biphenyl ether, which confers its chemical properties to many toxic compound including polychlorinated biphenyls (PCBs), bispenol A and dioxin [4].

TCS was invented over 40 years ago, but it has been used gradually more over the past few years and in 1998, worldwide annual production of TCS is about 1500 tons [5]. At present, TCS is one of the more usually detected contaminants in aquatic and global environments [6]. The popularity of antibacterial consumer products has led to increased consumer use of TCS [7] and personal care product are the main source of environment contamination of TCS, these product contain about around $0.1 \%$ to $0.3 \%$ (W/W) of TCS [8]. In China, TCS ranged from 11-478 ng/L in surface water, while in Pearl River system it ranged from 50-1330 ng/kg [9]. TCS has been detected in many human matrices, including human milk, urine and blood [10], while the National Health and Nutrition Examination Survey of 2003-2004, more than 70\% of U.S. residents had detectible TCS in their urine [11]. Thus, it shows the prevalent exposure of the general population to TCS.
Endocrine-Disrupting Chemicals (EDC) includes a variety of environmental contaminants that deadly affect the endocrine system [12]. The effects of anti-androgenic chemicals are dependent on the timing of exposure, but the periods of gestational and pubertal development are particularly susceptible. Despite its high occurrence across the ecosystem, the health effects of TCS have not been well studied. Recently, TCS is suspected to be a potential male reproductive toxicant. Many studies have demonstrated that TCS might have endocrine disrupting effects in animals and humans [13]. According to different studies, the mode of action of TCS as an EDC can be viz. estrogenic or weak androgenic or anti-androgenic. TCS has also been shown to function as an anti-androgen since it inhibits testosteroneinduced transcriptional activity [14]. Fourteen days TCS exposure in Japanese medaka fry (Oryzias latipes) suggested that TCS is potentially androgenic [15]. Another study reported that TCS has high toxicity on the early life stages of medaka, and the metabolite of TCS may be a weak estrogenic compound with the potential to induce vitellogenin in male medaka, as well as delaying the hatching in females [16]. Normal reproduction depends on the androgenic activity of animal [17], while, TCS treated rats showed depressed level of hormones production, which are most crucial components for testicular function. The aim of this review was to investigate the endocrine disrupting effects of TCS on male rats and to evaluate the mechanism.

\section{Toxicity of TCS}

Triclosan is a broad-spectrum antimicrobial drug and has been classified as a Class III drug by FDA [18]. TCS was declared as Priority Existing Chemical for full assessment under the Industrial Chemicals Act [6]. Contradictory findings have been found about the link between TCS and adverse health impacts in humans and animals.

Absorption, distribution, metabolism and excretion are rapid in the case of TCS in human body and are primarily excreted via urine. It has 
been reported that TCS exposure in human caused skin irritation [19]. Contact with TCS with further exposed to sunlight can trigger a Photo-Allergic Dermatitis (PACD) reaction, that can result in symptoms, like as irritation on the body parts [20], that might be due to long term work of active ingredient, consequently long-standing contact to TCS in turn increases the risk of PACD. Another area of concern is related to the hypothesis that TCS augments the production of chloroform. It was reported that TCS may engage in the production of chloroform, under specific conditions can almost double the chloroform formation in the drinking water treated with chlorine [21].

Toxicity of TCS also have been widely studied in various animal models, like in mice it was found that, TCS showed negative effect on the metabolism of thyroidal hormones, resulting hypothermia and generally depression of the central nervous system [22]. Similarly, the study reported that TCS treated rats showed significant decrease in sperm production [23]. Decrease in sperm production could be due to TCS interference with the metabolism of thyroid hormone. Another study in sheep pointed out that TCS can hinder the estrogen sulfotransferase activity and raises concern about its possible effects on the ability of the placenta to supply estrogen to the foetus, which would cause negative effects in the foetus development [24]. It was also reported that long term exposure to TCS in mice induced liver carcinoma [25]. Due to rising level of TCS in the environment, bacterial strains are more probable to acclimatize by developing resistance [26]. TCS has different vital medical applications; therefore the future objective must be to maintain these important applications while eliminating the gratuitous ones for its safe use.

\section{Effect on Male Reproductive Profile}

Data from wildlife and laboratory animal studies has increased apprehension that toxic chemicals might alter reproductive development in the human population. Numbers of factors are behind compromised male reproductive health including nutritional, lifestyle and environmental factors. In recent years, a large number of data has accumulated that suggests that the trend of decreasing male fertility might be due to misuse of medicine and due to exposure to environmental toxicants.

\section{Effect on reproductive organ}

The testicles are the male sex glands; produce sperm and testosterone. The seminiferous tubules and contents are the primary contributor to testicular weight. Testis size is highly correlated with fertility, poor fertility often being associated with small testis, as because process of spermatogenesis occurs in the seminiferous tubules of the testis and lower weight of testis is sign of smaller number or length of seminiferous tubules [17]. It was reported by Kumar et al. [23] that TCS treated group had decreased weights of testis, epididymis, ventral prostate, vas deferens and seminal vesicles between $20-50 \%$, including regressive histological changes in the seminiferous tubules resulting in the suppression of spermatogenesis. Disturbances in the synthesis of androgens have been reported due to use of TCS and it is well documented that androgenic disturbance causes negative changes in reproductive organ weights, as because constant androgenic stimulation is necessary for normal growth and functions of testis, epididymis and accessory sex organs [27]. Same result was also observed with other toxic compound like Prochloraz [28] and 5fluorouracil, including some environmental contaminant like PCBs [29], bispenol A [30] and dioxin [31].
On other hand, several other studies also suggested that TCS exhibited no significant negative effect on the weight of reproductive organ [32], the difference between results can be due to use of different method, environment and dose rate. In addition it is also have been reported that TCS treated rats group body weight was not significantly altered which is sign that TCS is not toxic to the animals as well as non-androgenic in nature, since androgens are known to possess anabolic activities like stimulating the development and growth of the skeleton and skeletal muscles.

\section{Effect on spermatogenesis}

Spermatogenesis is a complex process started at the early stage of fetal development including the division and differentiation of spermatogonial stem cells into mature spermatozoa. The spermatogenesis progression include the several phases, specifically the spermatocytes productions by mitotic proliferation of spermatogonial stem cells, following the division of spermatocyte to produce haploid round-spermatids, and in the last stage linking the early stages of round spermatids to be mature elongated-spermatids. During spermatogenesis together with germ and Sertoli cells, Leydig cells also play an important role; they produce testosterone, which is important for the maintenance of both secondary sexual functions and spermatogenesis [33]. It has been reported that TCS treated male rat showed significant decrease in the total number of sperm including decreased sperm motility, effectiveness and increased percentages of dead sperm [23]. Its shows that chemical that are toxic to the testis can alter the quantity and quality of the sperm produced via spermatogenesis resulting infertility problems in males. The decrease in number of sperm production can be due decreased testosterone production in TCS treated rat, which is important for sperm production [34].

Physiologically, testosterone is synthesized in Leydig cells under stimulation by Luteinizing Hormones (LH) [35], following LH binds to its receptor, and it stimulates adenylyl cyclase, resulting increased concentration of intracellular cAMP [36]. This increased level of cAMP, results the activation of various agents of steroidogenic cascade causing an amplified production of testosterone [37]. As Leydig cells are the primary site for testosterone, so the production of testosterone can be connected with testicular weight as because seminiferous tubules and contents are the primary contributor to testis weight. Decreased testicular weight in TCS treated rat means decreased seminiferous tubules and number of Leydig cells, resulted reduced testosterone production. Testosterone is the androgen that is important to regulate spermatogenesis. In fetal male rats, 3-5 days before birth serum testosterone levels are elevated and remains high until 8 days after birth. Testosterone level decrease gradually at reached up-to 0.2 $\mathrm{ng} / \mathrm{mL}$ after 8-24 days of birth [38]. In adults at (30-55 days) testosterone levels rise to $1-2 \mathrm{ng} / \mathrm{mL}$, stable adult level [39]. While, the physiological advantages of elevated testosterone levels is not clear, but the higher testicular concentration of testosterone is vital as because spermatogenesis process requires $70 \mathrm{ng} / \mathrm{mL}$ and spermatogenesis is considerably compromised at testosterone concentrations below 20 $\mathrm{ng} / \mathrm{mL}$ [40]. Thus, decreased testosterone level can be linked with lower sperm production, which can lead to infertility because fertility depends on the number of normal sperm produced. This depressed spermatogenesis could also be due to the reduced level of serum Follicle Stimulating Hormones (FSH), a hormone directly involved in maintaining spermatogenesis in conjunction with testosterone [34]. Depressed levels of androgens also reduce the sperm dynamics thereby affecting physiological maturation of the sperm resulting in reduced 
sperm count, motility, and density [41]. A study conducted by Raut and Angus [42] also reported the same effect of TCS in fish, according to their founding 35 days exposure of TCS to fish caused significant decreased sperm production.

With significant decrease in number of sperm due to improper spermatogenesis process, TCS treated rats also showed, decreased sperm motility, effectiveness and increase in the percentages of dead sperm, compared to control group [43]. Another study conducted by Wang et al. [32] reported that TCS Rats treated with the high dose (200 $\mathrm{mg} / \mathrm{kg}$ ) of TCS showed a significant decrease in daily sperm production, changes in sperm morphology and epididymal histopathology. Considering the histopathological change in the epididymis, TCS may induce the epididymal damage due to the epididymal accumulation of that. Toxic compound can damage the sperm cell by physiological, cytotoxic and genetic mechanisms and morphological abnormalities in sperm might have been caused by alterations in testicular DNA that in turn disrupts the process of differentiation of spermatozoa.

\section{Effect on steroidogenesis}

The synthesis of steroid hormones is one of the critical processes in the endocrine regulation. Most toxicants impair steroidogenesis and decrease Leydig cell function by inducing ROS and/or by decreasing the levels of steroidogenic enzymes. Steroidogenesis in Leydig cells involve numbers of steps and most of which are dependent on apposite concentrations of cAMP [44]. While, with the help of adenylyl cyclise, cAMP is produced, thus, an appropriate functioning of the enzyme adenylyl cyclase is vital for balanced steroidogenesis. The rate of steroidogenic pathway mainly depends on the transportation of cholesterol from outer to inner mitochondrial membrane with the help of transmembrane protein, while, steroidogenic acute regulatory protein (StAR) and suitable cAMP is crucial for this step [45].

Kumar et al. [23], reported that TCS treated rats showed, decreased cAMP concentration and a decreased expression of StAR protein, thus it shows that TCS have negative effects on production of steroid hormones, which are vital for normal reproductive performance in males and females. This depressed accessibility of cAMP could be due to decreased availability of ATP to the adenylyl cyclase enzyme or by a decreased performance of the enzyme itself. Another study carried out by Kumar et al. [46] to check TCS-induced anti-androgenecity in rat Leydig cells, also showed that TCS decrease the activity of adenylyl cyclase enzyme and in turn leads to the interference of intermediate steroidogenic flow resulting decreased testosterone production. After successful transportation of cholesterol to the inner mitochondrial membrane with help of StAR protein, for regulating the steroidogenesis, the expression and availability of cytochrome P450 side chain cleavage (P450SCC) enzyme is required [47], while TCS treated mouse showed depressed level [46]. The decreased P450SCC could be the outcome of a decreased availability of cholesterol in the inner mitochondrial membrane. 3-hydroxysteroid dehydrogenase ( $3 \beta$ HSD), $17 \beta$-hydroxysteroid dehydrogenase (17 $\beta$-HSD) are two critical enzymes in the steroidogenesis pathway, While in TCS treated rats these were also found in decreased level [23]. Decreased testosterone production in treated rat might be also due decreased expression and activity of P450SCC, $3 \beta$-HSD and $17 \beta-$ HSD enzymes, as a constant and stable status of all of them is required for an optimal testosterone synthesis.

In conclusion these findings showed that the P450SCC, $3 \beta$-HSD and $17 \beta-\mathrm{HSD}$ are important targets for the actions of EDC, while the initiation of this androgen inhibition starts, when EDC disrupts the activity of adenylyl cyclase enzyme. This leads to an abridged cAMP accessibility, and disturbed the whole cAMP-dependent steroidogenic pathway, resulting depressed StAR expression and down regulation of all key steroidogenic enzymes.

\section{Effect on histopathology}

The testis consists of two types of tissues: Seminiferous tubules, including Sertoli cells, and the interstitial compartment, including Leydig cells [48]. Efficiency of spermatogenesis depends on the integrity of the seminiferous tubules, Sertoli cells and endocrine regulation, while this process is regulated by testosterone and FSH. In response to $\mathrm{LH}$, Leydig cells produce androgen, like testosterone, which along with FSH bind to their respective Sertoli cell receptors to regulate spermatogenesis.

The tendency of chemicals, drugs and or compound to harm reproductive processes in animals and humans is of enormous distress to toxicologists and the public. Normal testicular functions (spermatogenesis, steroidogenesis) depend on normal histology of testis. It has been reported TCS treated rat showed a number of histopathological malformations, compared to control group [49], which possibly affect the production and maturation of the sperms. A study carried by Mahmoud and Solaiman [49] reported that TCS treated rat showed cytological and nuclear degenerative changes in seminiferous tubules, resulting significantly lowered number of germ cell, Sertoli cells, Leydig Cells, primary spermatogonia, secondary spermatogonia, and spermatocytes. These observations suggest that TCS have degenerative and retrogressive effects of TCS on rat testis. Kumar et al. [23] reported that several malformations were observed in the Lumina of epididymal tubule, vas deference, and prostate tissues, including reduced sperm density in epididymal tube. The decreased testosterone and androgenic receptor level in treated rats might have led to the degenerative changes and atrophy in the sex accessory tissue resulting decreased weight. It also shows that decreased sperm count in TCS treated rat could be due decrease spermatogenesis in testis. The reduction in rate of spermatogenesis is due to decreased FSH and testosterone production in testis, as production of these hormones depend on the normal integrity of Leydig and Sertoli cells. Degenerative changes observed in the cauda, ductus deferens and prostate glands might be attributed to the decrease in the level of androgen and androgen receptors which are known to support the functioning and continuous persistence of these organs.

\section{Conclusion}

TCS is commonly used chemical as an antimicrobial agent in various cosmetics and other applications. The frequent use of TCS and its subsequent entry into the environment is an alarm due to its deadly effects, so some regulations should be made to prevent its accumulation during the next decades. Infertility problems are increasing due to environmental contaminations and frequent use of therapeutic drugs. Present review literature showed that TCS act as an endocrine disruptor in male rats, it inhibits the production of androgen by reducing the LH and cholesterol production; depressed StAR expression and finally down-regulation of several key steroidogenic enzymes. It confirmations that TCS pose a hazard to human and animal's health, so, it is recommended that caution should be exercised in the use of it. 


\section{Acknowledgement}

Special thanks to Pharmaceutica Analytica Acta Journal for inviting and giving us a chance to share some knowledge.

\section{References}

1. Dhillon GS, Kaur S, Pulicharla R, Brar SK, Cledon M, et al. (2015) Triclosan: current status, occurrence, environmental risks and bioaccumulation potential. Int J Environ Res Public Health 12: 5657-5684.

2. Russell AD (2004) Whither triclosan? J Antimicrob Chemother 53: 693-695.

3. Ahn KC, Zhao B, Chen J, Cherednichenko G, Sanmarti E, et al. (2008) In vitro Biologic Activities of the Antimicrobials Triclocarban, Its Analogs, and Triclosan in Bioassay Screens: Receptor-Based Bioassay Screens. Environ Health Perspect 116: 1203-1210.

4. Allmyr M, Harden F, Toms LML, Mueller JF, McLachlan MS, et al. (2008) The influence of age and gender on triclosan concentrations in Australian human blood serum. Sci Total Environ 393: 162-167.

5. Bester K (2005) Fate of triclosan and triclosan-methyl in sewage treatment plants and surface waters. Arch Environ Contam Toxicol 49 9-17.

6. Dhillon SG, Kaur S, Pulicharla R, Brar KS, Cledon M, Verma M, et al. (2015) Triclosan: Current Status, Occurrence, Environmental Risks and Bioaccumulation Potential. Int J Environ Res Public Health 12 5657-5684.

7. Tan L, Nielsen NH, Young DC, Trizna Z (2002) Use of antimicrobial agents in consumer products. Arch Dermatol 138: 1082-1086.

8. McBain AJ, Rickard AH, Gilbert P (2002) Possible implications of biocide accumulation in the environment on the prevalence of bacterial antibiotic resistance. J Ind Microbiol Biotechnol 29: 326-330.

9. Zhao JL, Ying GG, Liu YS, Chen F, Yang JF, et al. (2010) Occurrence and risks of triclosan and triclocarban in the Pearl River system, South China: from source to the receiving environment. J Hazard Mater 179: 215-222.

10. Philippat C, Wolff MS, Calafat AM, Ye X, Bausell R, et al. (2013) Prenatal exposure to environmental phenols: concentrations in amniotic fluid and variability in urinary concentrations during pregnancy. Environ Health Perspect 121: 1225-1231.

11. Calafat AM, Ye X, Wong LY, Reidy JA, Needham LL (2008) Urinary Concentrations of Triclosan in the U.S. Population: 2003-2004. Environ Health Perspect 116: 303-307.

12. Cargouet M, Perdiz D, Mouatassim-Souali A, Tamisier-Karolak S, Levi Y (2004) Assessment of river contamination by estrogenic compounds in Paris area (France). Sci Total Environ 324: 55-66.

13. Matsumura N, Ishibashi H, Hirano M, Nagao Y, Watanabe N, et al. (2005) Effects of nonylphenol and triclosan on production of plasma vitellogenin and testosterone in male South African clawed frogs (Xenopus laevis). Biol Pharm Bull 28: 1748-1751.

14. Chen J, Ahn KC, Gee NA, Gee SJ, Hammock BD, et al. (2007) Antiandrogenic properties of parabens and other phenolic containing small molecules in personal care products. Toxicol Appl Pharmacol 221: 278-284.

15. Foran CM, Bennett ER, Benson WH (2000) Developmental evaluation of a potential non-steroidal estrogen: triclosan. Mar Environ Res 50: 153-156.

16. Ishibashi H, Matsumura N, Hirano M, Matsuoka M, Shiratsuchi H, et al. (2004) Effects of triclosan on the early life stages and reproduction of medaka Oryzias latipes and induction of hepatic vitellogenin. Aquat Toxicol 67:167-179.

17. Ibtisham F, Chen J, Niu Y, Wang Z, Wu J, et al. (2016) Effect of Aspirin on Reproductive Profile of Male Rat An-Overview. Int J Res Dev Pharm Life Sci 05: 5-12.
18. Courtney KD, Moore JA (1971) Teratology studies with 2,4,5trichlorophenoxyacetic acid and 2,3,7,8-tetrachlorodibenzo-P-dioxin. Toxicol Appl Pharmacol 20: 396-403.

19. Robertshaw H, Leppard B (2007) Contact dermatitis to triclosan in toothpaste. Contact Dermatitis 57: 383-384.

20. Schena D, Papagrigoraki A, Girolomoni G (2008) Sensitizing potential of triclosan and triclosan-based skin care products in patients with chronic eczema. Dermatol Ther 21: S35-38.

21. Fiss EM, Rule KL, Vikesland PJ (2007) Formation of chloroform and other chlorinated byproducts by chlorination of triclosan-containing antibacterial products. Environ Sci Technol 41: 2387-2394.

22. Miller TL, Lorusso DJ, Walsh ML, Deinzer ML (1983) The acute toxicity of penta-, hexa-, and heptachlorohydroxydiphenyl ethers in mice. J Toxicol Environ Health 12: 245-253.

23. Kumar V, Chakraborty A, Kural MR, Roy P (2009) Alteration of testicular steroidogenesis and histopathology of reproductive system in male rats treated with triclosan. Reprod Toxicol 27: 177-185.

24. James MO, Li W, Summerlot DP, Rowland-Faux L, Wood CE (2010) Triclosan is a potent inhibitor of estradiol and estrone sulfonation in sheep placenta. Environ Int 36: 942-949.

25. Yueh MF, Taniguchi K, Chen S, Evans RM, Hammock BD, et al. (2014) The commonly used antimicrobial additive triclosan is a liver tumor promoter. Proc Natl Acad Sci U S A 111: 17200-17205.

26. Khan R, Kong HG, Jung YH, Choi J, Baek KY, et al. (2016) Triclosan Resistome from Metagenome Reveals Diverse Enoyl Acyl Carrier Protein Reductases and Selective Enrichment of Triclosan Resistance Genes. Sci Rep 6: 32322.

27. Al ET, Chan K, Jensen N, Brien PJO (2008) Structure-activity relationships for thiol reactivity and rat or human hepatocyte toxicity induced by substituted p-benzoquinone compounds. J Appl Toxicol 28: 608-620.

28. Blystone CR, Furr J, Lambright CS, Howdeshell KL, Ryan Bryce C, et al. (2007) Prochloraz inhibits testosterone production at dosages below those that affect androgen-dependent organ weights or the onset of puberty in the male Sprague dawley rat. Toxicol Sci 97: 65-74.

29. Oishi S (2001) Effects of butylparaben on the male reproductive system in rats. Toxicol Ind Health 17: 31-39.

30. Manfo FPT, Jubendradass R, Nantia EA, Moundipa PF, Mathur PP (2014) Adverse effects of bisphenol A on male reproductive function. Rev Environ Contam Toxicol 228: 57-82.

31. Yonemoto J (2000) The effects of dioxin on reproduction and development. Ind Health 38: 259-268.

32. Wang LS, Wang L, Wang L, Wang G, Li ZH, et al. (2009) Effect of 1butyl-3-methylimidazolium tetrafluoroborate on the wheat (Triticum aestivum L.) seedlings. Environ Toxicol 24: 296-303.

33. Esakky P, Moley KH (2016) Paternal smoking and germ cell death: A mechanistic link to the effects of cigarette smoke on spermatogenesis and possible long-term sequelae in offspring. Mol Cell Endocrinol 435: 85-93.

34. Feng Y, Zhang P, Zhang Z, Shi J, Jiao Z, et al. (2016) Endocrine Disrupting Effects of Triclosan on the Placenta in Pregnant Rats. PLoS ONE 11: e0154758.

35. Lin H, Wang SW, Wang RY, Wang PS (2001) Stimulatory effect of lactate on testosterone production by rat Leydig cells. J Cell Biochem 83: 147-154.

36. Dufau ML (1988) Endocrine regulation and communicating functions of the Leydig cell. Annu Rev Physiol 50: 483-508.

37. Stocco DM, Clark BJ (1996) Role of the steroidogenic acute regulatory protein (StAR) in steroidogenesis. Biochem Pharmacol 51: 197-205.

38. Walker WH, Cheng J (2005) FSH and testosterone signaling in Sertoli cells. Reproduction 130: 15-28.

39. Ketelslegers JM, Hetzel WD, Sherins RJ, Catt KJ (1978) Developmental Changes in Testicular Gonadotropin Receptors: Plasma Gonadotropins and Plasma Testosterone in the Rat. Endocrinology 103: 212-222.

40. Zirkin BR, Santulli R, Awoniyi CA, Ewing LL (1989) Maintenance of Advanced Spermatogenic Cells in the Adult Rat Testis: Quantitative 
Citation: Ibtisham F, Nawab A, Zhao Y, Li G, Xiao M, et al. (2016) Effect of Antimicrobial Triclosan on Reproductive System of Male Rat. Pharm Anal Acta 7: 516. doi:10.4172/2153-2435.1000516

Page 5 of 5

Relationship to Testosterone Concentration within the Testis. Endocrinology 124: 3043-3049.

41. Grewall T, Mickelsen O, Hafs HD (1971) Androgen secretion and spermatogenesis in rats following semistarvation. Proc Soc Exp Biol Med 138: 723-727.

42. Raut SA, Angus RA (2010) Triclosan has endocrine-disrupting effects in male western mosquitofish, Gambusia affinis. Environ Toxicol Chem 29: 1287-1291.

43. Zorrilla LM, Gibson EK, Jeffay SC, Crofton KM, Setzer WR, et al. (2009) The effects of triclosan on puberty and thyroid hormones in male wistar rats. Toxicol Sci 107: 56-64.

44. Beavo JA, Brunton LL (2002) Cyclic nucleotide research -- still expanding after half a century. Nat Rev Mol Cell Biol 3: 710-718.
45. Manna PR, Dyson MT, Stocco DM (2009) Regulation of the steroidogenic acute regulatory protein gene expression: present and future perspectives. Mol Hum Reprod 15: 321-333.

46. Kumar V, Balomajumder C, Roy P (2008) Disruption of LH-induced testosterone biosynthesis in testicular Leydig cells by triclosan: Probable mechanism of action. Toxicology 250: 124-131.

47. Omura T, Morohashi K (1995) Gene regulation of steroidogenesis. J Steroid Biochem Mol Biol 53: 19-25.

48. Akingbemi BT (2005) Estrogen regulation of testicular function. Reprod Biol Endocrinol 3: 51.

49. Mahmoud SA, Solaiman AA (2014) Histological study of adult male rat seminiferous tubules following triclosan administration and the possible protective role of pomegranate juice. Egypt J Histol 37: 233-247. 